are paid by VISA; $7 \%$ by Mastercard/Access. Ruth Ann Stewart (Library of Congress) reported on the successful opening of LC's new store, which sells a mix of books, gift items, folk art, juvenalia, and stationary products.

Nigel Thorp (Glasgow University Library) recounted details of the exhibition The Glory of the Page, consisting of Renaissance and illuminated manuscripts from the Glasgow University Library. From initial planning to actual production the exhibition took nearly five years. Thorp personally supervised packing and unpacking at each exhibition site, driving a truck across Canada and North America (an adventure itself worthy of a book).

IGPL will next meet in 1991 in Cambridge, Massachusetts. The conference will be cosponsored by Harvard University and the Massachusetts Historical Society. As Jane Carr put it, "The issues have been raised; now solutions must be explored."
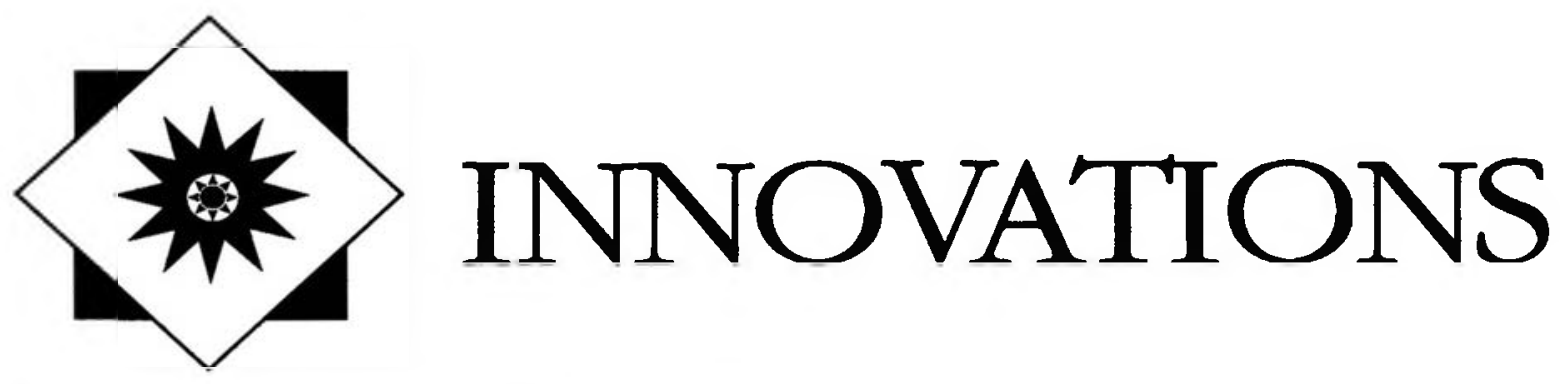

\title{
Humor and creativity: Basic technology
}

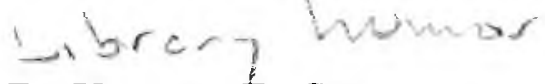

By Norman D. Stevens

Director, The Molesworth Institute
Those among us who are intelligent, and fortunate, enough to have become skilled information professionals have demonstrated that academic

\section{Feeling funny?}

Having taken leave of my peculiar pursuit of library humor for a brief period of time, I find I have become more irritable. Having taken leave of my senses, I have allowed the editor of $C \& R L$ News, and both of the readers who have responded positively to my efforts to date, to persuade me to resume my efforts to enlighten and amuse you by searching out and offering up these tales of creativity and humor in academic librarianship. For the time being my idle threat in the April 1989 issue to leave you to your own devices has been postponed. So I once again renew my quest for appropriate examples of this genre. Please send examples of your creativity, and that of your colleagues, to me at 143 Hanks Hill Road, Storrs, CT 06268 along withyou guessed it-your business card, a postcard of your library, or any other kind of library ephemera. librarians can master the complexities of a new information age with all of its new technologies. CD-ROMs, OPACs, and other mysterious firmware, hardware, software, and even vaporware don't faze some of us. We can hold our own with the other technocrats who have come to dominate academic communities.

Then there are the rest of us. For some academic librarians technology still is, as it has always been, a true test of our mettle. The incredible expertise of our more knowledgeable colleagues may utterly baffle us as we struggle with low technology or the simpler aspects of high technology. Fortunately it is most often the rudimentary aspects of the librarian's love affair with technology that provides us, when we are either frustrated or inspired, with our greatest opportunities to use humor to put technology and technocrats in their proper niche - the vacant recessed nook in the corridors of older libraries once reserved for the bust of Shakespeare.

\section{Paperclips}

That the challenge of the simpler forms of technology is not something new is amply demonstrated by the little known, and seldom recalled, contro- 
versy that raged in the pages of Library Journal in 1915. That learned dispute began when John B. Kaiser wrote to suggest that Gem paperclips be used to affix stamps enclosed with letters to the page rather than moistening a corner and sticking them on the page. Forrest Spaulding quickly pointed out that Gem clips were too long and often tore the stamps so he suggested that Ideal paperclips be used instead. That exchange naturally lead Edmund Lester Pearson to join the fray by inquiring if $\mathrm{Mr}$. Spaulding was "a safe guide in those larger fields of efficiency and equipment which are of such real importance to the librarian." He offered the Junior Gem paperclip (23 mm. x $5 \mathrm{~mm}$.) as a suitable alternative for the regular Gem paperclip (34 mm. $x 8 \mathrm{~mm}$.) adding, "surely these figures speak for themselves."

\section{Barcodes}

Today, even as the preservationists among us promote the advantages of plastic paperclips in preventing the kind of damage that $\mathrm{Mr}$. Spaulding lamented, there are many other simple aspects of technology that plague us. Chief among the minor nuisances of contemporary librarianship may well be the ubiquitous bar code label. Roy Tennant, of the library at the University of California at Berkeley, pointed out the challenges offered by those items as the very first piece in the very first issue (May 1988) of his Automated Circulation Newsletter: "Once again [he wrote] we are being overrun by thousands of little striped creatures. They travel in packs and have been sighted in three libraries on campus. There is only one way to overcome this scourge: separate individual barcodes from the pack and apply the little bugger to the inside back cover of a library item. There are so many of these creatures that the library staffs of the three afflicted libraries are unable to handle the epidemic alone." Subsequent issues of that newsletter have failed to reveal the degree of Mr. Tennant's success in enlisting volunteers as evidenced by the number ultimately awarded T-shirts "commemorating their bravery in the face of seemingly insurmountable odds."

\section{On/Off Switches}

Those who have finally mastered the tricks of barcoding most likely work in a library where computer terminals have come to dominate the scene. Even in the smallest contemporary academic library there may be a dazzling array of computer terminals presenting us with yet another basic challenge that brings out the best in us. All of the instructions, manuals, and training sessions that we receive too often overlook what we really need to know: how to turn the computer terminal on and off. In its April 1, 1985, issue, Torn Sheet, the alternative staff newsletter of the University of Wyoming Library, tackles that important issue in a creative story that consumes almost a full page.

There the Head of Machinery offers a careful and thoughtful explanation of the specific on and off procedure for each of the four different kinds of terminals found in that library (omitting the BDS terminals used only by highly trained specialists). Designed for novices, the explanation begins by pointing out that "on/off switches may be on the front, on the back, on the left, on the right, or on the bottom [but that] the library does not currently have any terminals with the switches on the top." Detailed instructions-"push the switch toward you if you are standing in front of it"-and appropriate cautions - "never turn this terminal off"are given. The piece concludes with the observation that even the Head of Machinery has not yet mastered the way in which a particular microcomputer is turned on but she offers to try to learn how to do so before revising her paper. Alas, those badly needed added instructions, to the best of my knowledge, never appeared; but a follow-up in the September 20, 1985, issue of Torn Sheet does offer an update for the latest Brodart terminal which remains on at all times and, therefore, has no on/off switch. The ingenuity of the University of Wyoming Library staff is matched only by my own staff in the technical services area of the University of Connecticut Library which, for a time, posted written instructions for start-up procedures next to each of several microcomputers.

Since we had suggested that those machines be locked at night for security reasons, the first instruction simply indicated where the key was to be found which was usually in an unlocked drawer of the desk on which the terminal sat.

\section{Pencil sharpeners}

Of all items of technology-low, medium, or high-to be found in academic libraries, none offers us a greater challenge, or a greater inspiration, than the ubiquitous pencil sharpener, be it manual, electric, or electronic. Surely in almost every academic library pencil sharpeners still outnumber computer terminals, although the day may yet come when the pencil sharpener, like the typewriter, is relegated to a dusty attic, basement, or closet. While they still predominate, they offer us ample opportunity for creativity and humor.

The earliest printed reference yet identified to the place of these essential tools in libraries is in a short 1972 series in The Lantern's Core from the Northwestern University Libraries. There several different staff members described in concise detail the precise kind ("Giant Apsco Sharpener") and exact location ("the north side of the reference room next to the out-of-town telephone directo- 
ries") of pencil sharpeners to be found in various parts of the library although they all somehow neglected to adequately describe how to locate the proper place to insert the pencil. As cited in slightly more detail in my earlier piece on the peculiar nature of music librarians, Stephen Fry, of the Music Library, concluded that three-part series with a longer than usual description of one gray Apsco "Giant" type III-A sharpener there that, in the usual perverse fashion of music librarians, had been installed in such a way that it is especially handy for left-handed people who were invited there just for that purpose.

A favorite sport of some law librarians, following an example set by one of the deans of their profession, is to offer law faculty and, especially, students the opportunity to ask written questions on any matter that strikes their fancy in a public notebook to which the law librarian himself, or herself as the case may be, subsequently responds in writing for all to read and be entertained by. In his notebooks Robert Berring, law librarian at the University of California, Berkeley, who started the whole thing, found two items relating to the important question of pencil sharpeners. One student asked what those "little bits of disgusting pencil shavings" that he finds on desks are and why people don't have the courtesy to clean up after themselves. Zeb, for so the respondent styles himself, pointed out that those are not, in fact, pencil shavings but "tiny bits of the outer layer of the brain stem" that "most first year law students shed...as a part of the first year process of acculturation." Those chips, which are highly toxic and not to be ingested, are collected and sold for reprocessing into memory chips for super computers. Another user asked Zeb if the fact that the electric pencil sharpeners always break is a plot. Zeb replied that it indeed was a plot that is part of a long-term clinical psychological study in frustration levels and that, actually, most of those sharpeners never actually worked at all.
Emily Greenberg, one of Berring's imitators, of the University of Baltimore Law Library, was asked by a student: "Is it possible to have a pencil sharpener installed on the fourth floor?" In her rather lengthy answer Ms. Greenberg analyzes the usual bureaucratic delays involved in the purchase process-even for something as simple as a pencil sharpener-and the several difficult problems faced in the selection of the ideal location: noise ("that old-fashioned non-electric hand-crank machine is going to upset some patrons"); eyes, ears, and other body parts ("you have to mount the machine at a height where even short people can reach it"); and aesthetics ("it grieves me to think of sullying the horizon with a little metal protuberance"). Ms. Greenberg ultimately concedes that a pencil sharpener will eventually be installed on the fourth floor.

The most intriguing library anecdote involving pencil sharpeners, which comes-alas-from a public library setting, is a brief tale recounted by Anita Gregory who now works at the Occidental College Library. In her earlier life as a public librarian Ms. Gregory once encountered a patron who came to the Circulation Desk and asked for the location of the men's room. "He was informed [Ms. Gregory writes] that it was kept locked, for his safety, and that the key was missing. He blinked, and without missing a beat, asked, 'Well then, do you have a pencil sharpener?'”

\section{Conclusion}

Surely if librarians can keep a straight face when faced with such improbable relationships, we can master any form of technology. The higher forms may broaden our horizons, expand our services, and offer our patrons entry into new forms of knowledge. The lower forms continue to limit our capabilities, restrict our services, and offer us entry into new forms of amusement.

\title{
Telephone information service
}

\author{
By Edward A. Riedinger
}

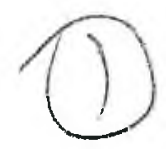

School of Library and Information Studies
University of California, Berkeley

The literature on telephone information or reference service has concentrated on this activity primarily as it is conducted in public library settings. Such research has been appearing for over half a century. However, telecommunication changes now occurring in academic libraries, from junior and community colleges to major research universities, will heighten the importance of telephone information service in them.

Online collection catalogs are now common- 